\title{
Transcription inhibitors prevent amnesia induced by NMDA antagonist-mediated impairment of memory reconsolidation
}

\author{
Vladimir P. Nikitin ${ }^{1}$ - Svetlana V. Solntseva ${ }^{1}$ • Alexey V. Shevelkin ${ }^{1,2}$
}

Published online: 7 January 2016

(C) Psychonomic Society, Inc. 2016

\begin{abstract}
Recent studies report that long-term memory retrieval can induce memory reconsolidation, and impairment of this reconsolidation might lead to amnesia. Previously, we found that reconsolidation of a conditioned food aversion memory could be disrupted by translation inhibitors for up to $3 \mathrm{~h}$ following a reconsolidation event, thus inducing amnesia. We examined the role of transcription processes in the induction of amnesia in the land snail, Helix lucorum. It received N-methyl-D-aspartate (NMDA) glutamate receptor antagonist and transcription inhibitor 2 days after learning in a neutral context environment; it was then transferred to the learning context followed by reminder with conditioned food stimulus. NMDA receptor blockade, followed by a reminder session, impaired reconsolidation of an aversive memory. Simultaneous administration of an NMDA receptor antagonist and a transcription inhibitor prior to reminder of an aversive event prevented amnesia induction. In contrast, when a transcription inhibitor alone was injected prior to a reminder session, the blockade had no effect on memory. We found that transcription inhibition 0-6 h after amnesia induction suppressed memory loss, but this suppression was lost when inhibitors were administered $9 \mathrm{~h}$ after amnesia. Thus, amnesia is
\end{abstract}

Vladimir P. Nikitin

vpnikitin48@gmail.com

Alexey V. Shevelkin

shevelkin@gmail.com

1 P.K. Anokhin Research Institute of Normal Physiology, Laboratory of Functional Neurochemistry, Russian Academy of Medical Sciences, Mokhovaya str. 11/4, 125009 Moscow, Russian Federation

2 Department of Psychiatry and Behavioral Sciences, Johns Hopkins University School of Medicine, 600 North Wolfe Street, CMSC 9-115, Baltimore, MD 21287, USA likely dependent on transcription processes within a 9-h time window. We can hypothesize that amnesia induction initiates synthesis of specific mRNAs and proteins; furthermore, these events occur within specific time-dependent windows. Our findings could prove useful for the analysis of amnesia formation and for the development of possible ways to prevent memory loss associated with various diseases and injuries in animals and humans.

Keywords Amnesia · Transcription inhibitor · NMDA glutamate receptor antagonist $\cdot$ Learning $\cdot$ Conditioned food aversion $\cdot$ Long-term memory $\cdot$ Reconsolidation $\cdot$ Snail $\cdot$ Helix lucorum

\section{Introduction}

Considerable progress has been made in understanding the neurophysiological and molecular mechanisms of long-term memory formation and stabilization (Dudai, 2004; Kandel, 2009; McGaugh, 2000). Amnestic processes such as memory loss, forgetting, and amnesia, are far less extensively studied, despite their theoretical, social, and medical importance. Increased interest in amnestic processes has been driven by new discoveries about long-term memory reconsolidation (Alberini et al., 2006; Dudai, 2004; Misanin et al., 1968; Nader \& Wang, 2006; Przybyslawski \& Sara, 1997; Riccio et al., 2006; Sara \& Hars 2006; Tronson \& Taylor, 2007). In particular, the reactivation of a previously consolidated memory has been shown to lead to its transformation into a labile state and to its potential destabilization. Once in the labile state, a previously consolidated memory can be modified by various manipulations within a certain time window (several hours after memory reactivation). However, after this sensitive 
period, the memory once again becomes stabilized (reconsolidated).

Despite evident progress in understanding memory consolidation and reconsolidation, mechanisms of amnesia caused by disruption of these processes remain unclear. It has been demonstrated that protein and RNA synthesis inhibitors, blockers of some neurotransmitter receptors (e.g., N-methylD-aspartate (NMDA) glutamate receptors), as well as inhibitors of intracellular protein kinases and transcription factors, can induce amnesia if they are administered when the previously consolidated memory is reactivated (Alberini et al., 2006; Anokhin et al., 2002; Cai et al., 2012; Gainutdinova et al., 2005; Nader \& Wang, 2006; Pedreira et al., 2002; Sara \& Hars, 2006; Tronson \& Taylor, 2007). For example, a reminder stimulus combined with administration of an RNA synthesis inhibitor (actinomycin D, $\alpha$-amanitin, or 5,6dichloro-1- $\beta$-D-ribofuranosylbenzimidazole (DRB)) has been shown to disrupt a Pavlovian-conditioned defensive reaction in the marine mollusk Hermissenda (Child et al., 2003), an operantly conditioned response in Lymnaea stagnalis (Sangha et al., 2003), spatial memory in the Morris water maze in rats (Da Silva et al., 2008), conditioned freezing in rats (Lee et al., 2004), and conditioned passive avoidance in both chicks (Sherry et al., 2010) and rats (Duvarci et al., 2008). NMDA receptors are involved in the reconsolidation of context-signal memory (Pedreira et al., 2002) as well as memory for object recognition (Akirav \& Maroun, 2006), passive avoidance (Summers et al., 2003; Suzuki et al., 2004) and conditioned feeding behavior (Cui et al., 2005; Lee \& Everitt, 2008; Torras-Garcia et al., 2005).

Our previous studies of Helix snails after classical conditioning of a food aversion (Solntseva \& Nikitin, 2011; Solntseva \& Nikitin, 2008; Solntseva et al., 2007) showed that presentation of a reminding food stimulus with simultaneous administration of a protein synthesis inhibitor or NMDA glutamate receptor antagonist induced amnesia. On the other hand, injections of RNA synthesis inhibitors prior to a reminder stimulus had no effect on memory storage (Solntseva \&
Nikitin, 2012). Thus, long-term memory reconsolidation depends on protein, but not mRNA, synthesis. Moreover, we found that amnesia did not develop in the case of simultaneous inhibition of NMDA receptors and protein synthesis prior to the reminder (Solntseva \& Nikitin, 2011) and could be prevented by repeated learning $0-10$ days after NMDA receptor inhibition/reminding (Solntseva \& Nikitin, 2010). We have thus hypothesized that the disruption of memory reconsolidation by NMDA receptor antagonists initiates amnesia, and that this process requires de novo protein synthesis (Nikitin \& Solntseva, 2012; Solntseva \& Nikitin, 2011). However, it remains unclear whether amnesia induced by disruption of memory reconsolidation depends on transcription processes.

In order to determine the sensitive period for amnesia development and to evaluate the role of transcription processes in the induction of amnesia, we studied the effects of transcription inhibitors (with either actinomycin D or DRB) administered simultaneously with an NMDA receptor antagonist (MK-801 or APV) before the reminder procedure (presentation of conditioned food stimulus). Next, to determine the time window during which amnesia is dependent on transcription, actinomycin D was administered 3, 6, or $9 \mathrm{~h}$ after NMDA receptor antagonist administration.

\section{Materials and methods}

\section{Subjects}

Experiments were performed on adult Helix lucorum L. snails (Crimea population) weighing 30-35 g. At least 2 weeks prior to the experiment and between experimental sessions, snails were kept in home boxes and received fresh raw carrots. Snails were deprived of food for 3 days before training. Snails received food after test no. 3 and were again deprived of food for 3 days before test no. 4 (Fig. 1). All experiments were performed according to the Guide for the Care and Use

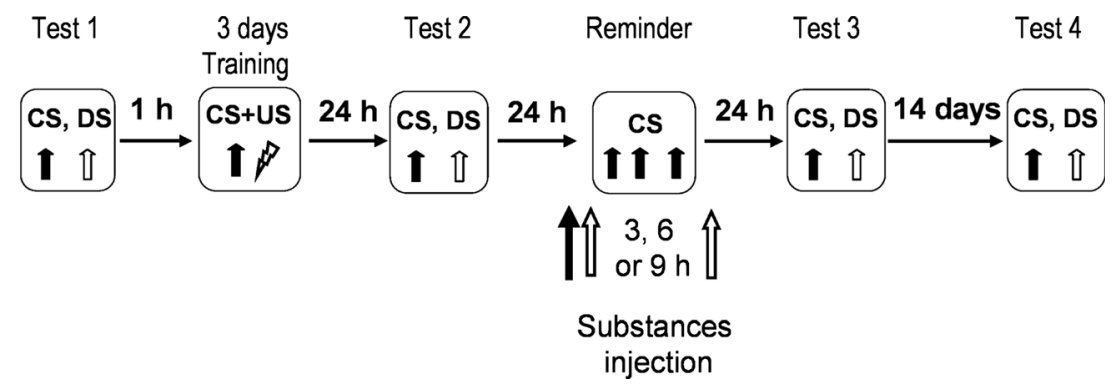

Fig. 1 Experimental procedure: food aversion conditioning, memory reconsolidation, and memory testing. N-methyl-D-aspartate (NMDA) receptor antagonists (MK-801 (dizocilpine maleate) or APV (DL-2amino-5-phosphonopentanoic acid)) and RNA synthesis inhibitors (actinomycin D or 5,6-dichloro-1- $\beta$-D-ribofuranosylbenzimidazole (DRB)) were singly injected or simultaneously injected before the reminder session. Additionally, actinomycin D was injected at 3,6, or $9 \mathrm{~h}$ after MK-801 and the reminder session. Long solid and open arrows indicate the moment of NMDA receptor antagonist or RNA synthesis inhibitor injections, respectively. $C S$ conditioned stimulus (banana), DS discriminative stimulus (boiled carrot), US unconditioned stimulus 
of Laboratory Animals published by the National Institute of Health.

\section{Learning}

Classical training of a conditioned food aversion was performed as described previously (Balaban, 1993; Solntseva \& Nikitin, 2012). Snails were tethered by their shells to brackets in a manner that allowed them to crawl freely on a ball floating in water with $0.01 \% \mathrm{NaCl}$. The plastic ball was wrapped with metal foil strips, and food was placed $0.5 \mathrm{~cm}$ from the snail's head. A banana and boiled carrot were used as the conditioned stimulus (CS) and discriminative stimulus (DS), respectively. An electric shock $(50 \mathrm{~Hz}, 300 \mathrm{~ms}, 1.2 \mathrm{~mA})$ served as the reinforcing stimulus. The electric shock was applied to the food and body of the snail after the first bite (consummatory reaction); one electrode was inserted into the food, while the other was placed in the water. Electrical stimulation led to the suppression of feeding behavior in response to the CS and induced a withdrawal reaction (retraction of the head and front part of the snail foot into the shell). Presentation of one DS alternated with the presentation of one to three CS. A significantly increased latency of the consummatory reaction (to 100-120 s) or complete refusal of banana during the 2-min test period served as the criterion of a conditioned food aversion. Presentation of food and consummatory reactions were recorded using a video camera and computer. Every 15 -20 min, food presentations were combined with electrical stimulation (4-6 times per day). Three training sessions were performed daily for 3 days, during which the CS was presented 12-16 times and the DS was presented 6-10 times.

\section{Reminder}

The snail was placed in the training context (on plastic balls), and 15-20 min later a reminder procedure was performed: the banana CS was presented three times at intervals of 10 $-15 \mathrm{~min}$. If the snail attempted to eat the banana during the reminder procedure, then the food was removed. Electric shock was never applied during the reminder procedure. One hour later, the snail was transferred from the ball to its home box.

\section{Testing}

Responses to food were tested for $1 \mathrm{~h}$ prior to training (Test 1 ) and 1 (Test 2), 3 (Test 3), and 17 (Test 4) days after training (Fig. 1). On all test days, snails were placed into the training context for $30 \mathrm{~min}$, during which the CS and DS were presented at 15-min intervals and the latency to show a consummatory reaction was measured over a 120 -s period. If the snail attempted to eat during the CS presentation, the test was stopped. Electric shock was never applied during testing.
Some snails were fed raw carrots (the DS, never associated with electric shock) between the third and fourth tests. These snails were deprived of food for 3 days before the fourth test.

\section{Substances and injections}

We tested the effects of transcription inhibitors (actinomycin D a n d D R B (5,6-dich loro- 1 - $\beta$ - D ribofuranosylbenzimidazole)) and NMDA glutamate receptor antagonists (MK-801 ((+)- MK-801 (dizocilpine maleate)) and APV (DL-2-amino-5-phosphonopentanoic acid)), all of which were purchased from Sigma-Aldrich (Makarenko st., 2/21, bld 1, \#22, Moscow, Russia). MK-801 and APV were dissolved in physiological saline $(0.9 \% \mathrm{NaCl})$, while transcription inhibitors were initially dissolved in DMSO and then in physiological saline to a final concentration of $0.2 \%$ DMSO. An intracoelomic injection $(0.25 \mathrm{ml}$ per snail) was performed with a fine needle via a non-sensitive part of the foot skin normally hidden under the shell. An inhibitor of transcription and/or NMDA glutamate receptors was injected 2 days after training in a neutral (non-training) context (on glass plate). Snails received a reminder 15-30 min after injection. The following doses were administered: $1 \mathrm{mg} / \mathrm{kg}$ of body weight for actinomycin D, $20 \mathrm{mg} / \mathrm{kg}$ for DRB, $0.25 \mathrm{mg} / \mathrm{kg}$ for MK-801, and $15 \mathrm{mg} / \mathrm{kg}$ for APV. Doses used were previously shown to affect learning in experimental animals, including snails (Child et al., 2003; Crow et al., 1997; Kiss et al., 2009; Sangha et al., 2003; Solntseva \& Nikitin, 2011; Solntseva et al., 2007; Watanabe et al., 2005). In addition, it has been shown that actinomycin D and DRB dose-dependently inhibit RNA synthesis in the neural ganglia of different species of mollusks (Crow et al., 1997; Fulton et al., 2005; Montarolo et al., 1986). Control snails received injections of DMSOcontaining saline at times matched to those during which experimental snails received drug injections. All injections and tests were performed in a blind manner.

\section{Animal groups}

Four groups of snails received either MK-801, APV, actinomycin D, or DRB before the reminder session. Three other groups received simultaneous injections of MK-801 and actinomycin D, MK-801 and DRB, or APV and actinomycin D. To determine the time window for which amnesia is dependent on transcription processes, actinomycin D was administered to three different groups of snails at 3, 6, and $9 \mathrm{~h}$ after the MK801/reminder session. For each injection, snails were transferred from their home cages to a neutral environment.

\section{Data analysis}

Data were averaged, and standard errors of means were calculated. The latency to show a consummatory reaction to the 
$\mathrm{CS}$ in snails receiving injections prior to the reminder session was compared with the latency of response to the DS, the latency of response to the CS (banana) before training in the same group, and the latency of response to the CS in snails that received saline prior to the reminder procedure. We used the nonparametric Mann-Whitney rank sum test to compare performance of two groups of snails, and the Wilcoxon signed rank test was used for comparison of performance of the same group.

\section{Results}

In naïve snails, the latency to show a consummatory response to food (banana or boiled carrot) was 20-35 s (Figs. 1, 2, 3, 4, and 5, Test 1). Twenty-four hours after training (Figs. 1, 2, 3, 4 , and 5 , Test 2 ), the latency of the consummatory reaction to the conditioned stimulus (CS, banana) in all groups tested was significantly longer than either the reaction to the discriminative stimulus (DS, boiled carrot) $(\mathrm{p}<0.0001)$ or the latency of the initial consummatory response to banana before training ( $\mathrm{p}$ $<0.0001)$.

\section{Administration of an NMDA glutamate receptor inhibitor prior to the reminder procedure disrupts memory reconsolidation}

Administration of MK-801 prior to the reminder procedure decreased the latency to show a consummatory response to the CS. When snails ( $\mathrm{N}=12$ per group) were tested 1 and 15 days after the reminder procedure, latencies of MK-801injected snails were shorter than in control (saline-injected, $\mathrm{n}=$ 8) snails (Mann-Whitney rank sum test, Test 3: p $<0.0001$; Test 4: $\mathrm{p}<0.0001)$ and did not differ from latencies to the DS (Wilcoxon signed-rank test, Test 3: $\mathrm{p}=0.89$; Test 4: $\mathrm{p}=0.71$ ) or from initial responses to banana before training (Wilcoxon, Test 3: $\mathrm{p}=0.42$; Test $4: \mathrm{p}=0.87$ ) (Fig. 2).

Administration of APV prior to the reminder procedure showed similar results $(n=8$, Fig. 2$)$. Latencies to the CS were shorter than in control (saline-injected) snails (MannWhitney, Test 3: $\mathrm{p}<0.0001$; Test 4: $\mathrm{p}<0.0001$ ); furthermore, latencies to the $\mathrm{CS}$ did not differ from responses to the DS (Wilcoxon, Test 3: $p=0.74$; Test $4: p=0.84$ ) or from initial latencies to the banana before training (Wilcoxon, Test $3: \mathrm{p}=$ 0.91; Test 4: $\mathrm{p}=0.94$ ).

Thus, administration of NMDA glutamate receptor antagonists before the reminder session disrupted long-term memory and induced amnesia in snails that persisted for at least 2 weeks.

\section{Administration of transcription inhibitors prior to the reminder procedure does not affect memory reconsolidation}

In contrast to the effects of NMDA receptor antagonists, inhibitors of transcription injected prior to the reminder procedure did not affect long-term memory. Thus, latencies to

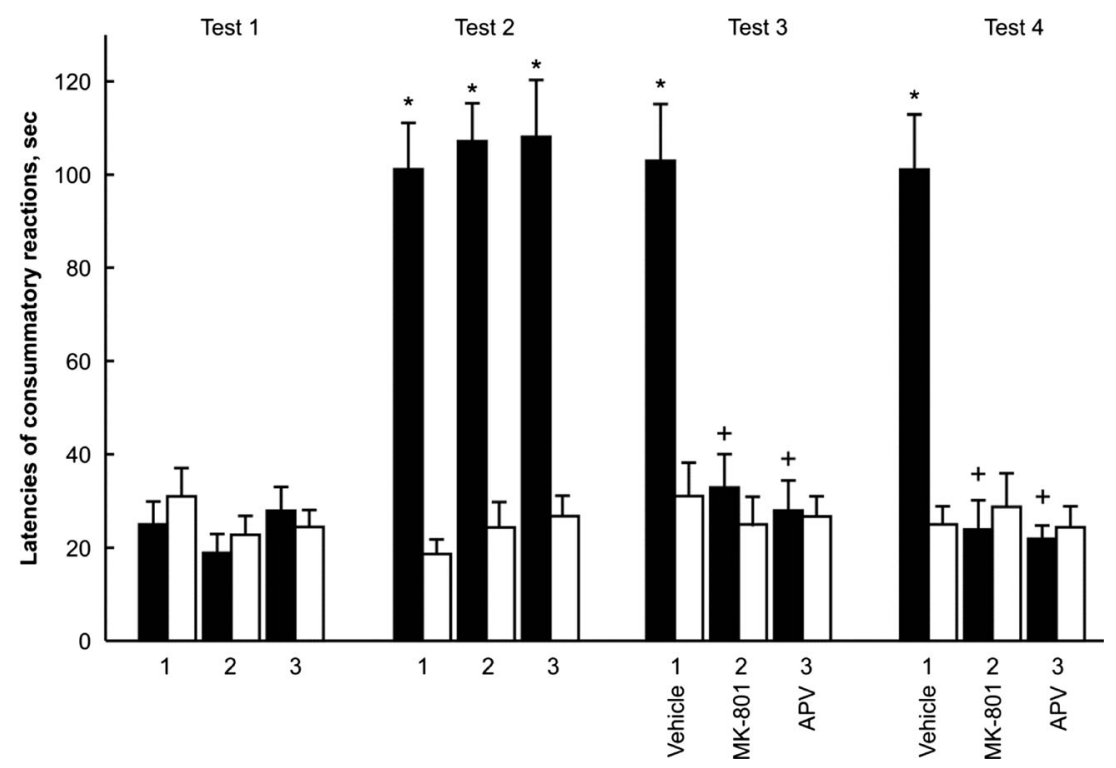

Fig. 2 Responses to the conditioned stimulus (CS) or discriminative stimulus (DS) in conditioned snails following injection of an N-methylD-aspartate (NMDA) receptor antagonist prior to the reminder session. Dark bars: responses to the CS (banana); open bars: responses to the DS (boiled carrot). Test 1: responses to the banana and boiled carrot prior to training; Test 2: $24 \mathrm{~h}$ after learning; Tests 3 and 4: 1 and 15 days, respectively, after injections of substances/delivery of the reminder (3 and 17 days after training). Group 1, vehicle injection; Group 2, injection of MK-801 (dizocilpine maleate) ; Group 3, injection of APV (DL-2-amino-5-phosphonopentanoic acid). Ordinate: averaged latency of consummatory reaction to food presentation. Data are presented as mean \pm SEM. $* \mathrm{p}<0.05$ (CS vs. DS and initial responses to banana before training); $+\mathrm{p}<0.05$ (CS in experimental vs. control snails) 


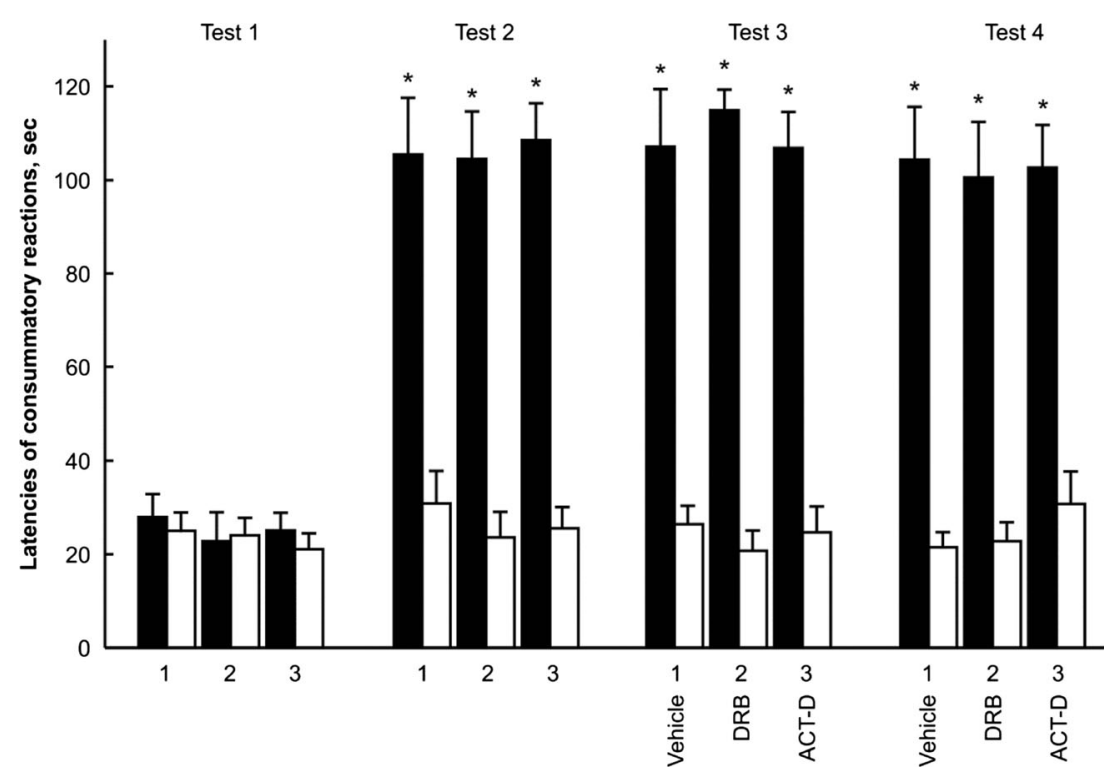

Fig. 3 Responses to the conditioned stimulus (CS) or discriminative stimulus (DS) after injection of an RNA synthesis inhibitor prior to the reminder. Dark bars: responses to the CS (banana); open bars: responses to the DS (boiled carrot). Test 1: responses to the banana and boiled carrot prior to training; Test 2: $24 \mathrm{~h}$ after learning; Tests 3 and 4: 1 and 15 days, respectively, after injections of substances/delivery of the reminder ( 3 and

respond to the CS after administration of $\mathrm{DRB}$ and the reminder procedure $(n=8)$ did not differ from the latencies of control (saline-injected) snails $(n=8)$ (Fig. 3), (Mann-
17 days after training). Prior to the reminder, snails were injected with either saline-containing 0.2\% DMSO (vehicle, Group 1), 5,6-dichloro-1$\beta$-D-ribofuranosylbenzimidazole (DRB) (Group 2), or actinomycin D (ACT-D, Group 3). ${ }^{*} \mathrm{p}<0.05$ (CS vs. DS and initial responses to banana before training)

Whitney, Test 3: $p=0.78$; Test 4: $p=0.99$ ) but were significantly longer than response latencies to the DS (Wilcoxon, Test 3: $\mathrm{p}=0.0078$; Test $4: \mathrm{p}=0.0078$ ) and the initial responses

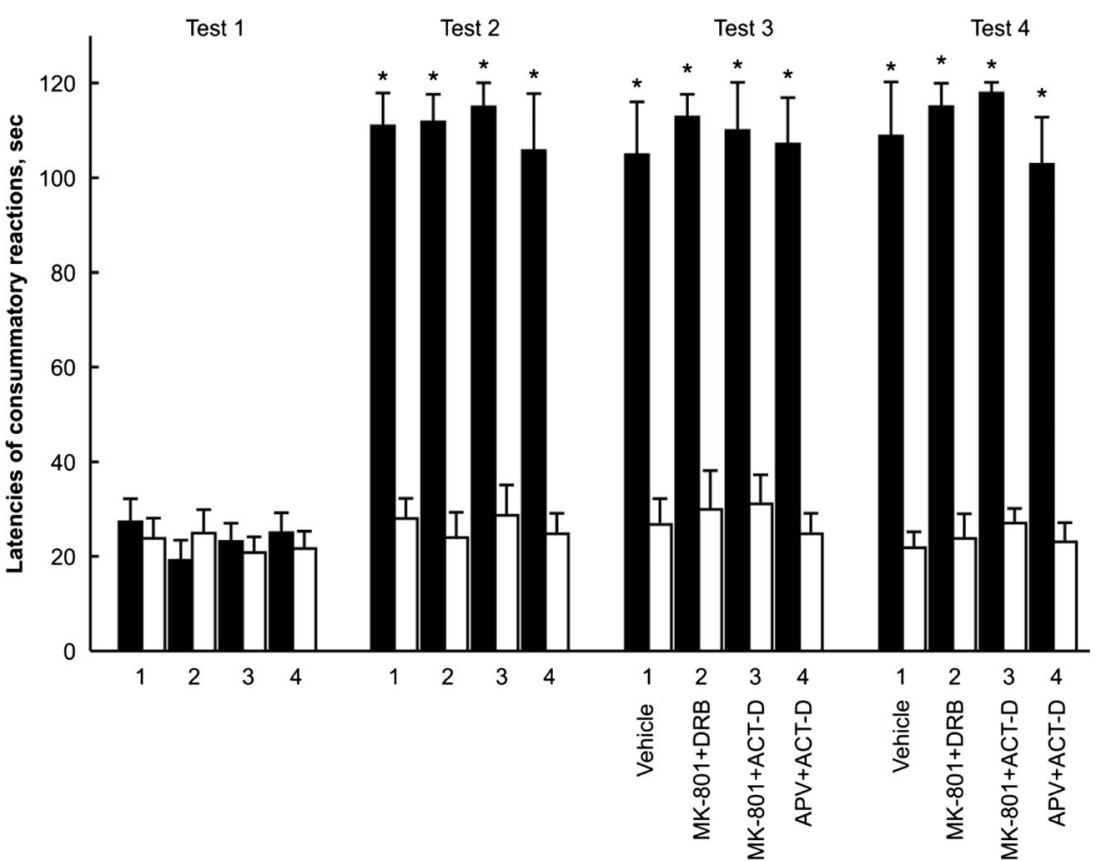

Fig. 4 Responses to the conditioned stimulus (CS) or discriminative stimulus (DS) after simultaneous injection of an N-methyl-D-aspartate (NMDA) receptor antagonist and RNA synthesis inhibitor prior to the reminder. Dark bars: responses to the CS (banana); open bars: responses to the DS (boiled carrot). Test 1: responses to the banana and boiled carrot prior to training; Test 2: $24 \mathrm{~h}$ after learning; Tests 3 and $4: 1$ and 15 days, respectively, after injections of substances/delivery of the reminder ( 3 and
17 days after training). Snails were injected with saline (Group 1), 5,6dichloro-1- $\beta$-D-ribofuranosylbenzimidazole (DRB) plus MK-801 (dizocilpine maleate) (Group 2), or actinomycin D (ACT-D) plus MK801(Group 3), or ACT-D plus APV (DL-2-amino-5-phosphonopentanoic acid) (Group 4). * p $<0.05$ (CS vs. DS and initial responses to banana before training) 


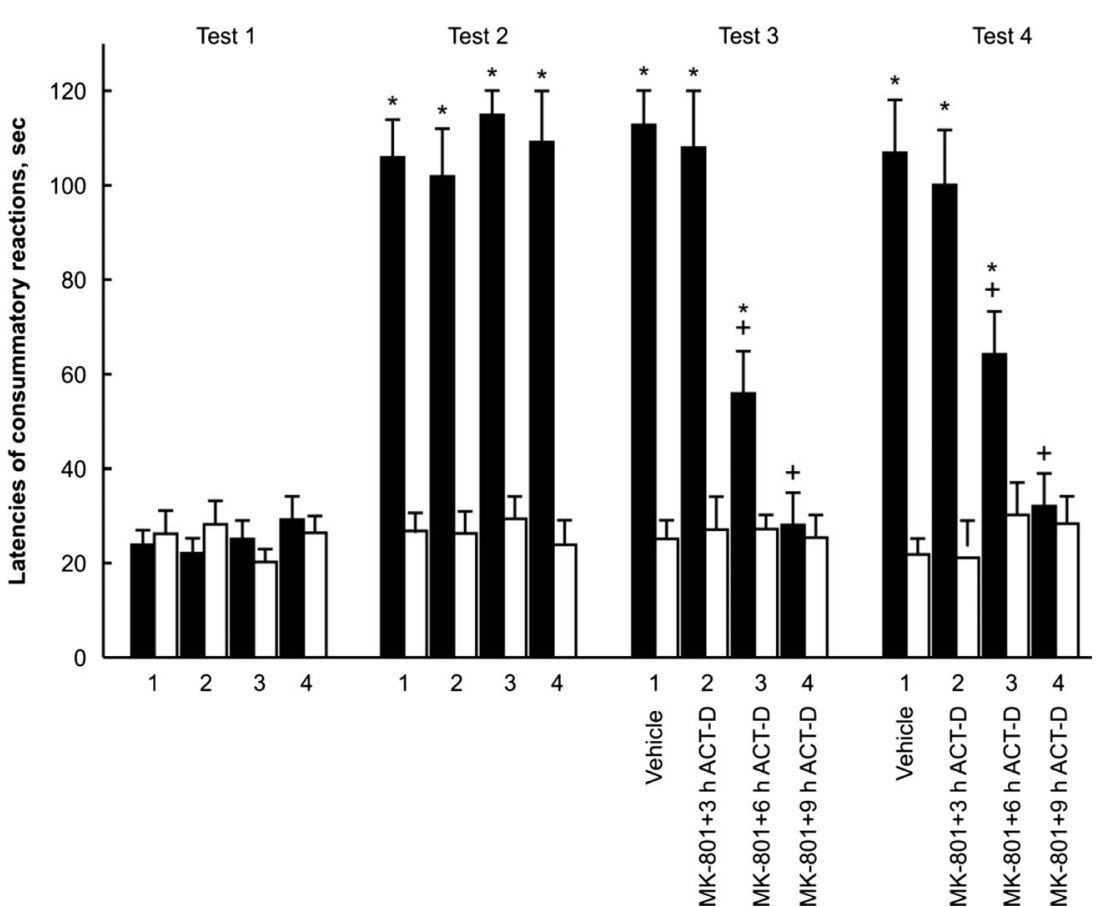

Fig. 5 Responses to the conditioned stimulus (CS) or discriminative stimulus (DS) following administration of actinomycin D (ACT-D) at 3 , 6 , or $9 \mathrm{~h}$ after dizocilpine maleate (MK-801) injection and exposure to the reminder stimulus. Dark bars: responses to the CS (banana); open bars: responses to the DS (boiled carrot). Test 1: responses to the banana and boiled carrot prior to training; Test 2: $24 \mathrm{~h}$ after learning; Tests 3 and 4: 1 and 15 days, respectively, after injections of substances/delivery of the reminder ( 3 and 17 days after training). ${ }^{*} \mathrm{p}<0.05$ (CS vs. DS and initial responses to banana before training) to the banana prior to training (Wilcoxon, Test 3: $p=0.0078$; Test 4: $\mathrm{p}=0.0078$ ).

Administration of actinomycin $\mathrm{D}$ prior to the reminder did not change response latencies to the CS in snails $(n=8)$ tested 1 and 15 days after the procedure (Fig. 3). The latencies of response to the CS did not differ from latencies of control (saline-injected) snails (Mann-Whitney, Test 3: $\mathrm{p}=0.99$; Test $4: p=0.86$ ), but they were significantly longer than response latencies to the DS (Wilcoxon, Test $3: \mathrm{p}=0.0078$; Test $4: p=0.0078)$ and initial responses to banana prior to training (Wilcoxon, Test 3: $\mathrm{p}=0.0078$; Test $4: \mathrm{p}=0.0078$ ). Thus, actinomycin D or DRB administered prior to the reminder procedure did not affect the maintenance of long-term memory for a conditioned food aversion.

\section{Simultaneous administration of a transcription inhibitor and NMDA receptor antagonist prior to the reminder prevents amnesia}

Two days after training, snails received simultaneous injections of an NMDA receptor antagonist and a transcription inhibitor before the reminder procedure. One and 15 days later (Fig. 4), latencies to the CS did not differ from those of control snails (Mann-Whitney, MK-801+DRB/reminder $(\mathrm{n}=8)$ : Test $3: p=0.57 ;$ Test $4: p=0.46 ;$ MK-801+actinomycin
D/reminder $(n=16)$ : Test 3: $p=0.61$; Test $4: p=0.83 ;$ APV + actinomycin $\mathrm{D} /$ reminder $(\mathrm{n}=8)$ : Test $3: \mathrm{p}=0.71$; Test $4: \mathrm{p}=$ 0.99 ). In addition, response latencies to the $C S$ were longer than latencies to the DS (Wilcoxon, MK-801+DRB/reminder: Test 3: $p<0.008$; Test 4: $p<0.008$; MK-801+actinomycin D/reminder: Test 3: $p<0.0001 ; \mathrm{p}<0.0001 ; \mathrm{APV}+$ actinomycin D/reminder: Test 3: $p=0.007$; Test $4: p=0.008)$ and responses to the banana prior to learning (Wilcoxon, MK801+DRB/reminder: Test 3: $p=0.008$; Test 4: $p=0.008$; MK-801+actinomycin D/reminder: Test 3: $\mathrm{p}<0.0001$; Test 4: $\mathrm{p}<0.0001 ;$ APV + actinomycin D/reminder: Test $3: \mathrm{p}=$ 0.008 ; Test $4: \mathrm{p}=0.008$ ). Thus, simultaneous administration of a transcription inhibitor (DRB or actinomycin D) and NMDA receptor antagonist (MK-801 or APV) prior to the reminder prevented the development of amnesia.

\section{The protective effect of transcription inhibition on memory is temporally graded}

To investigate the temporal gradient of amnesia sensitivity to a transcription inhibitor 2 days after training, the three groups of snails received an injection of MK-801 followed by the reminder procedure. Snails also received an injection of actinomycin D 3, 6, or $9 \mathrm{~h}$ after the MK-801/reminder. Response latencies to the CS did not differ from those of control snails 
(Mann-Whitney, Test 3: $\mathrm{p}=0.99$; Test 4: $\mathrm{p}=0.71$ ) and were longer than response latencies to the DS (Wilcoxon, Test $3: p$ $=0.008$; Test $4: \mathrm{p}=0.008)$ in snails $(\mathrm{n}=8) 1$ and 15 days after the MK-801/reminder followed by the actinomycin D injection at the 3-h interval (Fig. 5). Latencies to the CS surpassed those to the DS (Wilcoxon, Test 3: $\mathrm{p}=0.016$; Test $4: \mathrm{p}=$ 0.016 ) but were shorter than latencies to the CS in control snails (Mann-Whitney, Test 3: $\mathrm{p}=0.002$; Test 4: $\mathrm{p}=0.0036$ ) and in groups of snails $(n=8)$ that received the MK-801/ reminder followed by the actinomycin D injection at the 6-h interval (Fig. 5). Latencies to respond to the CS were shorter than those of control snails (Mann-Whitney, Test 3: $p=0.003$; Test 4: $p<0.0001)$, but did not differ from latencies to respond to the DS (Wilcoxon, Test 3: $p=0.99$; Test 4: $p=0.63$ ) in groups of snails $(n=8)$ that received the MK-801/reminder followed by the actinomycin D injection at the 9-h interval (Fig. 5). Thus, the vulnerability of amnesia to transcription inhibition was temporally graded; that is, an injection of actinomycin D $3 \mathrm{~h}$ after the MK-801/reminder completely prevented amnesia such that retrieval of the conditioned food aversion was not impaired, while injection of actinomycin D at $6 \mathrm{~h}$ resulted in partial amnesia, and injection of the transcription inhibitor at $9 \mathrm{~h}$ was not effective in preventing amnesia. In this latter group, long-term amnesia was observed up to 15 days after the MK-801/reminder.

\section{Discussion}

We have previously shown that administration of a protein synthesis inhibitor (cycloheximide or anisomycin) or an NMDA receptor antagonist (MK-801 or APV) prior to the presentation of a CS as a reminder of an aversive event can induce amnesia in snails that persists for more than 1 month (Solntseva \& Nikitin, 2008; Solntseva et al., 2007). However, injecting the protein synthesis inhibitor or NMDA receptor antagonist $3 \mathrm{~h}$ after the reminder had no effect on memory storage (Nikitin \& Solntseva, 2012a, b). Furthermore, simultaneous injections of a protein synthesis inhibitor and NMDA receptor antagonist prior to the reminder actually prevented amnesia from developing (Solntseva \& Nikitin, 2011). We also found that the protective effect of the protein synthesis inhibitor was temporally graded. In other words, if treatment with the protein synthesis inhibitor followed by the NMDA receptor antagonist/reminder was separated by more than a 6-h interval, then the long-term memory was disrupted (Solntseva \& Nikitin, 2011).

Previously, we observed that injecting an RNA synthesis inhibitor, such as actinomycin D or DRB, before a reminder event had no effect on memory storage in snails (Solntseva \& Nikitin, 2012). Thus, while protein synthesis inhibitors disrupt reconsolidation of conditioned food aversion memories, these findings confirmed that RNA synthesis inhibitors do not. Furthermore, this study suggested that the proteins required for memory reconsolidation are translated from pre-synthesized mRNAs that are stored in a "silent" state (Solntseva \& Nikitin, 2012). Many papers have in fact reported the reactivation of locally stored mRNAs after synaptic stimulation (Banerjee et al., 2009; Jarome et al., 2011; Parker \& Sheth, 2007; Zeitelhofer et al., 2008). Moreover, it has been shown that newly synthesized proteins are involved in specific morphological modifications of synaptic contacts that support long-term memory (Kandel, 2009; Parker \& Sheth, 2007; Redondo \& Morris, 2010).

Nevertheless, it seems that another mechanism of protein synthesis underlies the induction of amnesia observed in our experiments. In the present study, injecting an NMDA receptor antagonist (MK-801 or APV) prior to the reminder of an aversive memory induced amnesia. In contrast, simultaneous treatment with an NMDA receptor antagonist and an RNA synthesis inhibitor before the reminder event prevented the induction of amnesia. Thus, the mechanisms of amnesia induction, in contrast to those of memory reconsolidation, seem to depend on de novo RNA synthesis. Moreover, we found that mechanisms of NMDA-dependent amnesia are sensitive to RNA synthesis inhibitors within a time window of approximately $9 \mathrm{~h}$; specifically, actinomycin D prevented the development of amnesia when it was administered at 3 and $6 \mathrm{~h}$, but not at $9 \mathrm{~h}$ after injection of MK-801 during the reminder event.

Based on these findings, we propose that the CS reminder activates neurotransmitter receptors, including NMDA-type glutamate receptors, and the synthesis of proteins involved in memory reconsolidation. Because memory reconsolidation does not depend on transcription, we hypothesize that the necessary proteins are translated from pre-existing mRNAs stored at synapses involved in memory storage. Moreover, when NMDA receptors are inhibited during the reminder procedure, stored mRNAs are not activated, and protein synthesis necessary for memory reconsolidation does not occur.

The suppression of protein synthesis and memory reconsolidation does not address the question of why amnesia occurs. One possibility is that during memory reactivation, and after NMDA receptor inhibition, other neurotransmitter receptors initiate the molecular processes of amnesia induction. Mechanisms that underlie amnesia induction, in contrast to those of memory reconsolidation, depend on de novo mRNA synthesis. More specifically, it could be that synthesized mRNA and proteins initiate functional and morphological changes in neurons which specifically eliminate synapses formed during learning (Kandel, 2009), and as a result, suppress a response to the CS. Furthermore, the combined effect of NMDA receptor blockade and transcription or translation inhibition could suppress the synthesis of "amnestic" mRNAs and proteins, and block the development of amnesia. 
Thus, in these experiments we modeled a temporary deficiency of RNA and proteins and confirmed that amnesia development, as well as other adaptive and plastic processes in the brain (Davis \& Squire, 1984; Dudai, 2004; Fulton et al., 2005; Hawkins et al., 2006; Kandel, 2009; McGaugh, 2000), requires the synthesis of RNA and proteins, and occurs during a definite period of time after induction. According to these key characteristics, the mechanisms of amnesia induction are similar to mechanisms of memory consolidation; therefore, the induction of amnesia can be characterized as amnesia consolidation.

It may be assumed that in snails trained using the conditioned food aversion effect of glutamate NMDA receptor antagonists combined with a reminder, there is no progression to any impairment of the reconsolidation of memory and the development of amnesia, but rather to the extinction of memory entirely (Riccio et al., 2006). Our results, however, contradict this assumption. It is known that the extinction of memory is characterized by spontaneous recovery of memory after presentation of CS or US, as well as by placing animals in a different context (Dudai, 2004; Tronson \& Taylor, 2007). In our experiments, we did not observe the recovery of memory under these conditions (Solntseva \& Nikitin, 2011; Solntseva \& Nikitin, 2012a; Solntseva et al., 2007). We moreover found that at the late stage of development (i.e., 10 days after induction), amnesia acquires resistance to various effects, including re-learning (Solntseva \& Nikitin, 2010). Persistent amnesia cannot be explained by the extinction of memory, retrieval impairment, or the erasure of the so-called memory "footprint." In these cases, one would expect the recovery of memory or the formation of new memories following re-learning. This problem, however, requires further study.

In our experiments, we also revealed the existence of three distinct periods of amnesia development. (1) The first period of amnesia development was sensitive to transcription and translation inhibitors (Al-Ozairi et al., 2014; Solntseva \& Nikitin, 2011; Solntseva \& Nikitin, 2012), lasted 0-6 h after the induction of amnesia, and occurred by means of an NMDA receptor inhibitor/reminder stimulus. Administration of inhibitors $9 \mathrm{~h}$ after induction had no effects on amnesia development. (2) The second period of amnesia development was shown when we found that amnesia induced by a reminder and a simultaneous injection of an NMDA receptor inhibitor can be suppressed by repeated conditioning to the same stimulus (Solntseva \& Nikitin, 2010). The duration of this sensitive period was 10 days after the induction of amnesia. Moreover, it should be noted that it is possible to restore memory during these 10 days using the same conditioned stimulus, (3) but after that period we observed the third one when amnesia becomes irreversible (at least, within 30 days (Solntseva \& Nikitin, 2010; Solntseva et al., 2007)). Taken together, these findings suggest that the formation of amnesia takes place during a 10-day period and that de novo- synthesized inducible RNA and amnesia-associated proteins are involved. Furthermore, if repeated learning of a stored memory does not occur during this period, then amnesia becomes irreversible.

Acute amnesia is typically observed after brain injuries, post-traumatic stress (Mott et al., 2012; Ramos-Zúñiga et al., 2013), acute violations of the cerebral circulation, in some cases of epilepsy (Bartsch \& Butler, 2013; Lim \& Alexander, 2009), as a side effect after electroconvulsive therapy (Gregory-Roberts et al., 2010; Semkovska \& McLoughlin, 2013), drug addiction (Tronson \& Taylor, 2007), and during some psychosomatic disease conditions (Grant et al., 2010; Tannenbaum et al., 2012). We can speculate that amnesia develops as a useful and adaptive reaction of the brain to negative memories and to heavy emotional experiences. The features of amnesia development revealed in the present study could be useful for the analysis of amnesia formation and in the search for possible ways to prevent memory loss associated with various diseases and injuries in animals and humans.

In summary, we determined that memory reconsolidation depends on translation but not transcription, whereas amnesia induced by injection of an NMDA receptor antagonist after a reminder procedure depends on both translation and transcription processes. Moreover, we found that proteins and mRNAs involved in amnesia induction are synthesized during a time interval of approximately $9 \mathrm{~h}$ after a reminder event. The present results support our hypothesis (Solntseva \& Nikitin, 2011) that amnesia is an active process, developing in snails over several days, and that the mechanisms of its induction involve the synthesis of specific mRNAs and proteins.

Acknowledgments The authors are grateful to Prof. Vladimir Sherstnev for fruitful discussion and helpful comments.

The present research is supported by the Russian Foundation for Basic Research (project no. 13-04-01540). The authors declare no conflicts of interest.

\section{References}

Akirav, I., \& Maroun, M. (2006). Ventromedial prefrontal cortex is obligatory for consolidation and reconsolidation of object recognition memory. Cerebral Cortex, 16(12), 1759-1765.

Alberini, C. M., Milekic, M. H., \& Tronel, S. (2006). Mechanisms of memory stabilization and de-stabilization. Cellular and Molecular Life Sciences, 63, 999-1008.

Al-Ozairi, A., McCullagh, S., \& Feinstein, A. (2014). Predicting posttraumatic stress symptoms following mild, moderate, and severe traumatic brain injury: The role of posttraumatic amnesia. Journal of Head Trauma Rehabilitation, 8, 1-7.

Anokhin, K. V., Tiunova, A. A., \& Rose, S. P. R. (2002). Reminder effects-reconsolidation or retrieval deficit? Pharmacological dissection with protein synthesis inhibitors following reminder for a passive avoidance task in young chicks. European Journal of Neuroscience, 15(11), 1759-1765. 
Balaban, P. M. (1993). Behavioral neurobiology of learning in terrestrial snails. Progress in Neurobiology, 41(1), 1-19.

Banerjee, S., Neveu, P., \& Kosik, K. S. (2009). A coordinated local translational control point at the synapse involving relief from silencing and MOV10 degradation. Neuron, 64(6), 871-884.

Bartsch, T., \& Butler, C. (2013). Transient amnesic syndromes. Nature Reviews Neurology, 9(2), 86-97.

Cai, D., Pearce, K., Chen, S., \& Glanzman, D. L. (2012). Reconsolidation of Long-Term Memory in Aplysia. Current Biology, 22(19), 17831788.

Child, F. M., Epstein, H. T., Kuzirian, A. M., \& Alkon, D. L. (2003). Memory reconsolidation in Hermissenda. The Biological Bulletin, 205(2), 218-219.

Crow, T., Siddiqi, V., \& Dash, P. K. (1997). Long-term enhancement but not short-term inhermissendals is dependent upon mRNA synthesis. Neurobiology of Learning and Memory, 68(3), 343-350.

Cui, Z., Lindl, K. A., Mei, B., Zhang, S., \& Tsien, J. Z. (2005). Requirement of NMDA receptor reactivation for consolidation and storage of nondeclarative taste memory revealed by inducible NR1 knockout. European Journal of Neuroscience, 22(3), 755-763.

Davis, H. P., \& Squire, L. R. (1984). Protein synthesis and memory: A review. Psychological Bulletin, 96(3), 518.

Dudai, Y. (2004). The neurobiology of consolidations, or, how stable is the engram? Annual Review of Psychology, 55, 51-86.

Duvarci, S., Nader, K., \& LeDoux, J. E. (2008). De novo mRNA synthesis is required for both consolidation and reconsolidation of fear memories in the amygdala. Learning \& Memory, 15(10), 747-755.

Fulton, D., Kemenes, I., Andrew, R. J., \& Benjamin, P. R. (2005). A single time window for protein synthesis dependent long-term memory formation after one trial appetitive conditioning. European Journal of Neuroscience, 21(5), 1347-1358.

Gainutdinova, T. H., Tagirova, R. R., Ismailova, A. I., Muranova, L. N., Samarova, E. I., Gainutdinov, K. L., \& Balaban, P. M. (2005). Reconsolidation of a context long-term memory in the terrestrial snail requires protein synthesis. Learning \& Memory, 12(6), 620 625

Grant, K. S., Burbacher, T. M., Faustman, E. M., \& Gratttan, L. (2010). Domoic acid: Neurobehavioral consequences of exposure to a prevalent marine biotoxin. Neurotoxicology and Teratology, 32(2), 132141

Gregory-Roberts, E. M., Naismith, S. L., Cullen, K. M., \& Hickie, I. B. (2010). Electroconvulsive therapy-induced persistent retrograde amnesia: Could it be minimised by ketamine or other pharmacological approaches? Journal of Affective Disorders, 126(1), 39-45.

Hawkins, R. D., Kandel, E. R., \& Bailey, C. H. (2006). Molecular mechanisms of memory storage in Aplysia. Biological Bulletin, 210(3), 174-191

Jarome, T. J., Werner, C. T., Kwapis, J. L., \& Helmstetter, F. J. (2011). Activity dependent protein degradation is critical for the formation and stability of fear memory in the amygdala. PLoS One, 6(9), e24349.

Kandel, E. R. (2009). The biology of memory: A forty-year perspective. Journal of Neuroscience, 29(41), 12748-12756.

Kiss, T., Pirger, Z., \& Kemenes, G. (2009). Food-aversive classical conditioning increases a persistent sodium current in molluscan withdrawal interneurons in a transcription dependent manner. Neurobiology of Learning and Memory, 92(1), 114-119.

Lee, J. L. C., \& Everitt, B. J. (2008). Appetitive memory reconsolidation depends upon NMDA receptor-mediated neurotransmission. Neurobiology of Learning and Memory, 90(1), 147-154.

Lee, J. L. C., Everitt, B. J., \& Thomas, K. L. (2004). Independent cellular processes for hippocampal memory consolidation and reconsolidation. Science, 304(5672), 839-843.

Lim, C., \& Alexander, M. P. (2009). Stroke and episodic memory disorders. Neuropsychologia, 47(14), 3045-3058.
McGaugh, J. L. (2000). Memory-a century of consolidation. Science, 287(5451), 248-251.

Misanin, J. R., Miller, R. R., \& Lewis, D. J. (1968). Retrograde amnesia produced by electroconvulsive shock after reactivation of a consolidated memory trace. Science, 160(3827), 554-555.

Montarolo, P. G., Goelet, P., Castellucci, V. F., Morgan, J., Kandel, E. R., $\&$ Schacher, S. (1986). A critical period for macromolecular synthesis in long-term heterosynaptic facilitation in Aplysia. Science, 234(4781), 1249-1254.

Mott, T. F., McConnon, M. L., \& Rieger, B. P. (2012). Subacute to chronic mild traumatic brain injury. American Family Physician, 86(11), 1045-1051.

Nader, K., \& Wang, S. H. (2006). Fading in. Learning \& Memory, 13, $530-553$

Nikitin, V. P., \& Solntseva, S. V. (2012a). Induction of amnesia evoked by impairment to memory reconsolidation by glutamate or serotonin receptor antagonists is suppressed by protein synthesis inhibitors. Neuroscience and Behavioral Physiology, 42(4), 416-423.

Nikitin, V. P., \& Solntseva, S. V. (2012b). Mechanisms of amnesia induced by impairment of long-term memory reconsolidation in edible snail. Bulletin of Experimental Biology and Medicine, 153(5), 609613.

Parker, R., \& Sheth, U. (2007). P bodies and the control of mRNA translation and degradation. Molecular Cell, 25(5), 635-646.

Pedreira, M. E., Pérez-Cuesta, L. M., \& Maldonado, H. (2002). Reactivation and reconsolidation of long-term memory in the crabChasmagnathus: Protein synthesis requirement and mediation by NMDA-type glutamatergic receptors. Journal of Neuroscience, 22(18), 8305-8311.

Przybyslawski, J., \& Sara, S. J. (1997). Reconsolidation of memory after its reactivation. Behavioural Brain Research, 84(1), 241-246.

Ramos-Zúñiga, R., González-de la Torre, M., Jiménez-Maldonado, M., Villaseñor-Cabrera, T., Bañuelos-Acosta, R., Aguirre-Portillo, L., ... Jáuregui-Huerta, F. (2013) Postconcussion syndrome and mild head injury: The role of early diagnosis using neuropsychological tests and functional magnetic resonance/spectroscopy. World Neurosurgery: S1878-8750.

Redondo, R. L., \& Morris, R. G. M. (2010). Making memories last: The synaptic tagging and capture hypothesis. Nature Reviews Neuroscience, 12(1), 17-30.

Riccio, D. C., Millin, P. M., \& Bogart, A. R. (2006). Reconsolidation: A brief history, a retrieval view, and some recent issues. Learning Memory., 13(5), 536-544.

Sangha, S., Scheibenstock, A., \& Lukowiak, K. (2003). Reconsolidation of a long-term memory in Lymnaea requires new protein and RNA synthesis and the soma of right pedal dorsal 1. Journal of Neuroscience, 23(22), 8034-8040.

Sara, S. J., \& Hars, B. (2006). In memory of consolidation. Learning \& Memory, 13(5), 515-521.

Semkovska, M., \& McLoughlin, D. M. (2013). Measuring retrograde autobiographical amnesia following electroconvulsive therapy: Historical perspective and current issues. Journal of ECT, 29(2), 127-133.

Sherry, J. M., Milsome, S. L., \& Crowe, S. F. (2010). The roles of RNA synthesis and protein translation during reconsolidation of passiveavoidance learning in the day-old chick. Pharmacology Biochemistry and Behavior, 94(3), 438-446.

Silva, D., Weber, C., Bonini, J. S., Bevilaqua, L. R. M., Medina, J. H., Izquierdo, I., \& Cammarota, M. (2008). Inhibition of mRNA synthesis in the hippocampus impairs consolidation and reconsolidation of spatial memory. Hippocampus, 18(1), 29-39.

Solntseva, S. V., \& Nikitin, V. P. (2008). Serotonin and NMDA glutamate receptor antagonists selectively impair the reactivation of associative memory in the common snail. Neuroscience and Behavioral Physiology, 38(7), 687-693 
Solntseva, S. V., \& Nikitin, V. P. (2010). Reversible and irreversible stages in the development of amnesia after disruption of the reactivation of associative memory in snails. Neuroscience and Behavioral Physiology, 40(6), 679-686.

Solntseva, S. V., \& Nikitin, V. P. (2011). Protein synthesis is required for induction of amnesia elicited by disruption of the reconsolidation of long-term memory. Neuroscience and Behavioral Physiology, 41(6), 654-662.

Solntseva, S., \& Nikitin, V. (2012). Conditioned food aversion reconsolidation in snails is impaired by translation inhibitors but not by transcription inhibitors. Brain Research, 1467, 42-47.

Solntseva, S. V., Nikitin, V. P., Kozyrev, S. A., Shevelkin, A. V., Lagutin, A. V., \& Sherstnev, V. V. (2007). Effects of protein synthesis inhibitors during reactivation of associative memory in the common snail induces reversible and irreversible amnesia. Neuroscience and Behavioral Physiology, 37(9), 921-928.

Summers, M. J., Crowe, S. F., \& Ng, K. T. (2003). Memory retrieval in the day-old chick: A psychobiological approach. Neuroscience \& Biobehavioral Reviews, 27(3), 219-231.

Suzuki, A., Josselyn, S. A., Frankland, P. W., Masushige, S., Silva, A. J., \& Kida, S. (2004). Memory reconsolidation and extinction have distinct temporal and biochemical signatures. Journal of Neuroscience, 24(20), 4787-4795.

Tannenbaum, C., Paquette, A., Hilmer, S., Holroyd-Leduc, J., \& Carnahan, R. (2012). A systematic review of amnestic and nonamnestic mild cognitive impairment induced by anticholinergic, antihistamine, GABAergic and opioid drugs. Drugs \& Aging, 29(8), 639-658.

Torras-Garcia, M., Lelong, J., Tronel, S., \& Sara, S. J. (2005). Reconsolidation after remembering an odor-reward association requires NMDA receptors. Learning \& Memory, 12(1), $18-22$.

Tronson, N. C., \& Taylor, J. R. (2007). Molecular mechanisms of memory reconsolidation. Nature Reviews: Neuroscience, 8(4), 262-275.

Watanabe, H., Takaya, T., Shimoi, T., Ogawa, H., Kitamura, Y., \& Oka, K. (2005). Influence of mRNA and protein synthesis inhibitors on the long-term memory acquisition of classically conditioned earthworms. Neurobiology of Learning and Memory, 83(2), 151-157.

Zeitelhofer, M., Karra, D., Macchi, P., Tolino, M., Thomas, S., Schwarz, M., ... Dahm, R. (2008) Dynamic interaction between P-bodies and transport ribonucleoprotein particles in dendrites of mature hippocampal neurons. Journal of Neuroscience 28(30): 7555-7562. 